\title{
PENGARUH CITRA MEREK, KEPERCAYAAN MEREK, DAN KEAMANAN PRIVASI TERHADAP KEPUTUSAN PENGGUNA GOJEK
}

\author{
Valentine Teja Wijaya ${ }^{1}$, Bruno Hami Pahar ${ }^{2 *}$ \\ ${ }^{1,2}$ Program Studi Manajemen Fakultas Ekonomi Universitas Katolik Darma Cendika \\ Jalan Dr. Ir. H. Soekarno No. 201, Surabaya \\ *Corresponding Author: bruno.hami@ukdc.ac.id
}

\begin{abstract}
Gojek is an Indonesian technology company engaged in services through motorcycle taxi services. Gojek itself has more than 20 services offered and is a solution to everyday challenges, ranging from transportation, food delivery, shopping, delivery of goods, payments, massages, to cleaning houses and vehicles. Researchers conducted research on Gojek application users in Surabaya. This research is a research with quantitative method. The sampling technique used is purposive sampling and uses questions on a questionnaire distributed to 75 respondents who are Gojek application users who are at least 17 years old and have used the Gojek application in Surabaya at least 2 times. This research was conducted using validity test, reliability test, descriptive test, classical assumption test (normality test, multicollinearity test, heteroscedasticity test), multiple linear regression test, determinant coefficient, $F$ test, and t test. The $t$-test in this study states that the brand image variable (X1) on purchasing decisions $(Y)$ has a t-count value of $1.624<t$-table 1.993 with a significant level of $0.109>0.050$ which means that brand image has no effect on purchasing decisions of Gojek application users, the trust variable brand (X2) on purchasing decisions $(Y)$ has a $t$ value of $3.209>t$ table 1.993 with a significant level of $0.002<0.050$ which means that brand trust affects the purchasing decisions of Gojek application users, and the privacy security variable (X3) on purchasing decisions $(Y)$ has a $t$ value of $4.018>t$ table of 1.993 with a significant level of $0.000<0.050$ which means that privacy security affects the purchasing decisions of Gojek application users. The results of this study conclude that brand trust and privacy security have a significant effect on the decisions of Gojek users in Surabaya, while brand image does not affect the decisions of Gojek users in Surabaya.
\end{abstract}

Keywords: brand image, brand trust, privacy security, user decision.

\footnotetext{
ABSTRAK

Gojek adalah sebuah perusahaan teknologi Indonesia yang bergerak di bidang jasa melalui jasa ojek. Gojek sendiri memiliki lebih dari 20 layanan yang ditawarkan
} 
dan menjadi solusi untuk tantangan sehari-hari, mulai dari transportasi, pesan antar makanan, belanja, kirim barang, pembayaran, pijat, sampai bersih-bersih rumah dan kendaraan. Peneliti melakukan penelitian terhadap pengguna aplikasi Gojek di Surabaya. Penelitian ini merupakan penelitian dengan metode kuantitatif. Teknik pengambilan sampel yang digunakan adalah purposive sampling dan menggunakan pertanyaan pada kuesioner yang disebar kepada 75 responden yang merupakan pengguna aplikasi Gojek yang berumur minimal 17 tahun dan minimal telah menggunakan aplikasi Gojek di Surabaya sebanyak 2 kali. Penelitian ini dilakukan dengan menggunakan uji validitas, uji reliabilitas, uji deskriptif, uji asumsi klasik (uji normalitas, uji multikolinieritas, uji heteroskedastisitas), uji regresi linear berganda, koefisien determinan, uji F, dan uji t. Uji t pada penelitian ini menyatakan bahwa variabel citra merek (X1) terhadap keputusan pembelian (Y) memiliki nilai t hitung 1,624 < t tabel 1,993 dengan tingkat signifikan 0,109>0,050 yang berarti bahwa citra merek tidak berpengaruh terhadap keputusan pembelian pengguna aplikasi Gojek, variabel kepercayaan merek (X2) terhadap keputusan pembelian (Y) memiliki nilai $t$ hitung 3,209 > t tabel 1,993 dengan tingkat signifikan 0,002 <0,050 yang berarti kepercayaan merek berpengaruh terhadap keputusan pembelian pengguna aplikasi Gojek, dan variabel keamanan privasi (X3) terhadap keputusan pembelian (Y) memiliki nilai t hitung 4,018> t tabel 1,993 dengan tingkat signifikan 0,000< 0,050 yang berarti bahwa keamanan privasi berpengaruh terhadap keputusan pembelian pengguna aplikasi Gojek. Hasil dari penelitian ini menyimpulkan bahwa kepercayaan merek dan keamanan privasi berpengaruh signifikan terhadap keputusan pengguna Gojek di Surabaya, sedangkan citra merek tidak berpengaruh terhadap keputusan pengguna Gojek di Surabaya.

Kata kunci: citra merek, kepercayaan merek, keamanan privasi, keputusan pengguna.

\section{PENDAHULUAN}

Gojek adalah sebuah perusahaan teknologi Indonesia yang bergerak di bidang jasa melalui jasa ojek. Perusahaan yang didirikan pada tahun 2010 oleh Nadiem Makarim ini, sudah tersedia di 50 kota di Indonesia. Hingga pada bulan Juni 2016, aplikasi Gojek sudah diunduh sebanyak hampir 10 juta kali di Google Play pada sistem operasi android, maupun di App Store di sistem operasi IOS (Wikipedia, 2015). Gojek sendiri memiliki lebih dari 20 layanan yang ditawarkan dan menjadi solusi untuk tantangan sehari-hari, mulai dari transportasi, pesan antar makanan, belanja, kirim barang, pembayaran, pijat, sampai bersih-bersih rumah, dan kendaraan. Perkembangan ekosistem baru dari tradisional menuju ke digital memberikan dampak besar bagi pemenuhan kebutuhan masyarakat. Dengan kemajuan teknologi informasi dan komunikasi yang melahirkan aplikasi Gojek dan semacamnya telah memanjakan masyarakat dengan berbagai layanan yang diberikan. Saat ini dengan berbagai aplikasi yang ada termasuk Gojek 
membuat masyarakat dapat melakukan berbagai aktivitas tanpa dibatasi lagi dengan dimensi ruang dan waktu.

Munculnya aplikasi Gojek kemudian diikuti dengan berbagai layanan aplikasi yang sejenis, karena aplikasi layanan semacam ini diyakini akan menjadi model bisnis masa depan. Persaingan yang tinggi mengharuskan Gojek untuk mampu mempertahankan dan meningkatkan keputusan pembelian oleh para konsumen untuk dapat menggunakan aplikasi Gojek. Tjiptono (2014: 21) menyatakan bahwa keputusan pembelian merupakan suatu rangkaian proses yang dilakukan oleh seluruh konsumen dalam mengenali suatu produk dengan cara mencari informasi terkait produk ataupun merek, memutuskan pembelian, dan melakukan evaluasi akan penggunaan produk tersebut.

Kehadiran Gojek pada dunia bisnis memberikan kesempatan bagi masyarakat untuk memenuhi kebutuhan mereka dengan cara yang singkat dan sederhana, yaitu dengan menerapkan sistem digital dan saluran internet. Pelayanan jasa dengan sistem digital ini juga dapat menjadi pertimbangan oleh para konsumen, khususnya dalam hal bertransaksi. Terdapat beberapa hal yang menjadi alasan konsumen dalam memberikan keputusan untuk menggunakan Gojek, antara lain adalah citra merek, kepercayaan merek, dan keamanan privasi.

\section{TINJAUAN PUSTAKA \\ Pengertian Citra Merek}

Sudaryono (2016: 223) menunjukkan bahwa citra merek (brand image) adalah strategi yang dibuat bertujuan dengan memasukkan kepribadian sebuah citra ke dalam produk atau jasa, untuk kemudian dimasukkan ke alam bawah sadar konsumen. Citra merek merupakan representasi dari keseluruhan persepsi konsumen terhadap sebuah merek dan dibentuk dari informasi dan pengalaman masa lalu terhadap merek itu sendiri (Herliza dan Saputri, 2016).

\section{Pengertian Kepercayaan Merek}

Rizan et al. (2012) menunjukkan bahwa kepercayaan kepada merek merupakan pemikiran konsumen tentang keandalan yang didasari pada pengalaman, atau lebih pada urutan pemakaian atau interaksi yang dirasakan sesuai dengan harapan pada sebuah produk yang telah memberi kepuasan. Kepercayaan terjadi karena adanya harapan dan keinginan konsumen yang dapat terpenuhi. Yudhistira dan Asim (2019) menjelaskan bahwa kepercayaan merek merupakan persepsi akan kemampuan dari sudut pandang konsumen didasarkan pada pengalaman, atau lebih pada urut-urutan transaksi atau interaksi yang dicirikan oleh terpenuhinya harapan terhadap kinerja produk dan loyalitas pelanggan.

\section{Pengertian Keamanan Privasi}

Menurut Richards and Hartzog (2016) privasi penting karena memungkinkan kepercayaan konsumen. Aturan privasi mengatur penggunaan informasi dan aturan yang dapat membangun kepercayaan konsumen. Aturan mengenai privasi dapat mempromosikan kepercayaan yang memungkinkan konsumen dengan aman mengungkapkan informasi pribadi dengan cara 
menguntungkan, bukan hanya secara individu tetapi juga entitas mereka dalam berbagi data. Menurut Anggara et al. (2015: 3) perlindungan privasi dibuat untuk mengatur perilaku orang lain yang dapat mengganggu dengan berbagai cara pada privasi orang lain. Privasi dalam konteks ini dapat dipahami secara umum, yaitu membatasi kemampuan orang lain untuk mendapatkan, menyebarkan, atau menggunakan informasi tentang diri sendiri, atau orang lain.

\section{Pengertian Keputusan Pembelian}

Menurut Kotler (2014: 184) keputusan pembelian konsumen yaitu keputusan akhir konsumen yang membeli barang dan jasa untuk digunakan atau konsumsi pribadi. Menurut Setiadi (2014: 17) keputusan yang diambil oleh konsumen dapat disebut sebagai sebuah pemecahan masalah. Dalam proses pengambilan keputusan, konsumen memiliki sasaran atau keinginan yang ingin dicapai atau dipuaskan.

\section{Penelitian Terdahulu}

Mamahit et al. (2015) menyatakan bahwa citra merek dan kepercayaan merek berpengaruh terhadap keputusan pembelian. Ali et al. (2019) menyatakan bahwa citra merek dan kepercayaan merek tidak berpengaruh terhadap keputusan pembelian. Farohi (2017: 111) menyatakan bahwa keamanan privasi berpengaruh terhadap keputusan pembelian. Wahyuningsih (2016) menyatakan bahwa keamanan privasi tidak berpengaruh terhadap keputusan pembelian.

Berdasarkan penelitian terdahulu tersebut, maka kerangka konseptual yang digunakan di dalam penelitian ini seperti terlihat pada Gambar 1. Penelitian ini akan melihat pengaruh citra merek, kepercayaan merek, dan keamanan privasi terhadap keputusan pembelian pengguna Gojek di Surabaya. Adapun pengaruh antar variabel pada penelitian ini terlihat pada Gambar 1.

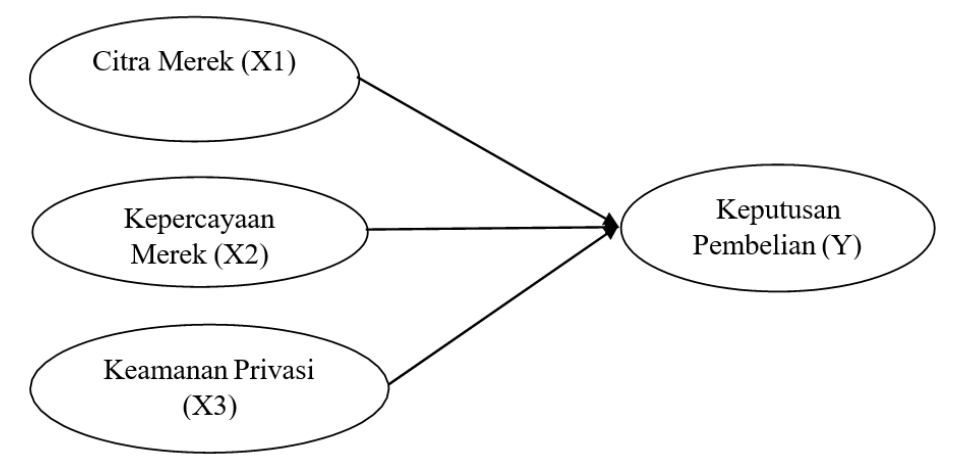

Gambar 1

Kerangka Konseptual

\section{Hipotesis Penelitian}

Penelitian ini memiliki 3 hipotesis yang akan diuji. Hipotesis tersebut adalah sebagai berikut: 
H1 : Citra merek berpengaruh terhadap keputusan pembelian pengguna Gojek di Surabaya.

$\mathrm{H} 2$ : Kepercayaan merek berpengaruh terhadap keputusan pembelian pengguna Gojek di Surabaya.

H3 : Keamanan privasi berpengaruh terhadap keputusan pembelian pengguna Gojek di Surabaya.

\section{METODE PENELITIAN}

Pendekatan penelitian yang digunakan adalah pendekatan kuantitatif. Penelitian kuantitatif merupakan penelitian yang berlandaskan tentang filsafat positivisme untuk meneliti populasi atau sampel tertentu dan pengambilan sampel secara random dengan pengumpulan data menggunakan instrumen, atau analisis data bersifat statistik. Populasi yang digunakan dalam penelitian ini yaitu pengguna aplikasi Gojek di Surabaya yang berumur minimal 17 tahun ke atas dan minimal telah menggunakan aplikasi Gojek di Surabaya sebanyak 2 kali. Sumber data penelitian ini berasal dari data primer dan data sekunder. Data primer dalam penelitian ini adalah kuesioner yang telah disebar dan diisi oleh 75 pengguna Gojek di Surabaya. Pengambilan sampel sumber data dilakukan secara purposive sampling, yaitu pengambilan sampel dengan cara memberikan ciri khusus dan sesuai tujuan penelitian.

Teknik pengumpulan data yang akan digunakan dalam penelitian ini yaitu menggunakan skala Likert. Indikator penelitian ini diambil berdasarkan teori para ahli, yaitu sebagai berikut:

1. Variabel Citra Merek menurut Ferrinadewi (2009: 166) adalah:

a. Kualitas sebuah produk atau jasa.

b. Pelayanan yang disediakan.

c. Kebijakan perusahaan.

d. Reputasi perusahaan.

2. Variabel Kepercayaan merek menurut Delgado-Ballester and MunueraAlema'n (2005) adalah:

a. Achieving Result (pemenuhan janji kepada konsumen).

b. Acting with Integrity (bertindak dengan integritas).

c. Demonstrate Concern (kepedulian).

3. Variabel Keamanan Privasi menurut Raman and Viswanathan (2011) adalah:

a. Jaminan keamanan.

b. Kerahasiaan data.

4. Variabel Keputusan Pembelian menurut Kotler dan Keller dalam Zulyanecha (2013: 52) adalah:

a. Pilihan produk.

b. Pilihan merek.

c. Pilihan penyalur.

d. Waktu pembelian.

e. Jumlah pembelian.

f. Metode pembayaran. 


\section{HASIL PENELITIAN DAN PEMBAHASAN \\ Karakteristik Responden}

Karakteristik responden pada penelitian ini menunjukkan bahwa mayoritas pengguna aplikasi Gojek di Surabaya berusia 17-25 tahun sebesar 86,7 \% dan tingkat frekuensi transaksi yang dilakukan sebanyak lebih dari 2 kali transaksi yaitu sebesar $90,7 \%$.

\section{Hasil Penelitian}

\section{Uji Validitas dan Reliabilitas}

Hasil uji validitas pada penelitian ini menyatakan bahwa setiap item pernyataan dapat dikatakan valid karena nilai $r$ hitung $\geq \mathrm{r}$ tabel yaitu 0,227 . Hasil ini menunjukkan bahwa seluruh item pernyataan dinyatakan valid. Hasil uji reliabilitas menyatakan bahwa semua variabel memiliki Cronbach's Alpha di atas 0,60 sehingga dapat dikatakan masing-masing variabel yang diajukan ke responden konsisten dan reliabel.

\section{Uji Deskriptif}

\section{Analisis Pengguna Gojek Terhadap Citra Merek}

Hasil analisis pengguna Gojek terhadap citra merek menyatakan bahwa ratarata pengguna Gojek sangat setuju terhadap citra merek. Nilai rata-rata terbesar terdapat pada penyataan bahwa layanan jasa yang diberikan Gojek memiliki kualitas yang baik.

\section{Analisis Pengguna Gojek Terhadap Kepercayaan Merek}

Hasil analisis pengguna Gojek terhadap kepercayaan merek menyatakan bahwa rata-rata pengguna Gojek sangat setuju terhadap kepercayaan merek. Nilai rata-rata terbesar terdapat pada pernyataan bahwa pengguna aplikasiGojek sangat setuju bahwa aplikasi Gojek memiliki fitur bantuan untuk membantu masalah yang dialami pengguna.

\section{Analisis Pengguna Gojek Terhadap Keamanan Privasi}

Hasil analisis pengguna Gojek terhadap keamanan privasi menyatakan bahwa pengguna Gojek setuju terhadap keamanan privasi. Nilai rata-rata terbesar terdapat pada pernyataan yang menyatakan bahwa perusahaan dan mitra driver Gojek mampu menjamin keamanan privasi pengguna.

\section{Analisis Pengguna Gojek Terhadap Keputusan Pembelian}

Hasil analisis pengguna Gojek terhadap keputusan pembelian menyatakan bahwa pengguna Gojek setuju terhadap keputusan pembelian. Nilai rata-rata terbesar terdapat pada pernyataan yang menyatakan bahwa pengguna aplikasi Gojek memilih aplikasi Gojek karena metode pembayarannya sangat mudah.

\section{Uji Normalitas, Multikolinieritas, dan Heteroskedastisitas}

Hasil uji normalitas pada penelitian ini menyatakan bahwa model regresi ini berdistribusi normal. Hal ini dapat dilihat dari diagram normalitas yang menunjukkan bahwa titik-titik dari kurva normalitas hasil uji yang terlihat 
menyebar di sekitar garis diagonal serta penyebarannya terlihat mengikuti garis diagonal.

Hasil uji multikolinearitas pada penelitian menunjukkan bahwa tolerance value $>0,1$ sedangkan nilai VIF $<10$ yang artinya tidak ada gejala multikolinearitas antar variabel independen pada model regresi. Hasil uji heteroskedastisitas pada penelitian ini menunjukkan bahwa penyebaran titik-titik pada kurva berada di atas dan di bawah angka 0 pada sumbu y dan tidak membentuk pola yang jelas sehingga dapat dikatakan tidak terjadi heteroskedastisitas pada model regresi

\section{Uji Regresi Linear Berganda}

Hasil regresi linear berganda pada penelitian ini memiliki persamaan yang dapat dirumuskan sebagai berikut:

$$
\mathrm{Y}=5,375+0,234 \mathrm{X} 1+0,638 \mathrm{X} 2+0,896 \mathrm{X} 3
$$

\section{Uji Koefisien Determinasi $\left(\mathbf{R}^{2}\right)$}

Hasil koefisien determinasi $\left(\mathrm{R}^{2}\right)$ pada penelitian ini menunjukkan bahwa nilai adjusted $R$ square sebesar 0,448 atau $44,8 \%$ yang artinya seluruh variabel independen berkontribusi sebanyak $44,8 \%$ terhadap variabel dependen dan tergolong pada tingkat kontribusi sedang.

\section{Uji F}

Hasil uji $\mathrm{F}$ pada penelitian ini menunjukkan bahwa nilai signifikan $0,00<$ 0,05 yang artinya bahwa variabel-variabel independen mampu menjelaskan fenomena yang dianalisis sehingga layak untuk diteliti.

\section{Uji t}

\section{Uji t Variabel Citra Merek Terhadap Keputusan Pembelian}

Hasil pengujian pengaruh variabel citra merek (X1) terhadap keputusan pembelian (Y) menghasilkan nilai t hitung 1,624 < t tabel 1,993 dengan tingkat signifikan 0,109 >0,050, yang artinya H0 diterima dan H1 ditolak, atau dapat dikatakan bahwa citra merek tidak berpengaruh terhadap keputusan pembelian pengguna aplikasi Gojek.

\section{Uji t Variabel Kepercayaan Merek Terhadap Keputusan Pembelian}

Hasil pengujian pengaruh variabel kepercayaan merek (X2) terhadap keputusan pembelian (Y) menghasilkan nilai t hitung 3,209 > t tabel 1,993 dengan tingkat signifikan 0,002 <0,050, yang artinya $\mathrm{H} 0$ ditolak dan $\mathrm{H} 1$ diterima, atau dapat dikatakan kepercayaan merek berpengaruh terhadap keputusan pembelian pengguna aplikasi Gojek.

\section{Uji t Variabel Keamanan Privasi Terhadap Keputusan Pembelian}

Hasil pengujian pengaruh variabel keamanan privasi (X3) terhadap keputusan pembelian (Y) menghasilkan nilai t hitung 4,018 > t tabel 1,993 dengan tingkat signifikan $0,000<0,050$, yang artinya $\mathrm{H} 0$ ditolak dan $\mathrm{H} 1$ diterima, atau 
Pengaruh Citra Merek, Kepercayaan Mereß, dan Keamanan Privasi Terhadap Keputusan Pengguna Gojek

Valentine Teja Wijaya dan Bruno Hami Pahar

dapat dikatakan keamanan privasi berpengaruh terhadap keputusan pembelian pengguna aplikasi Gojek.

\section{Pembahasan}

\section{Pengaruh Citra Merek Terhadap Keputusan Pembelian}

Citra merek tidak berpengaruh terhadap keputusan pembelian pengguna aplikasi Gojek. Artinya konsumen dalam memutuskan dalam pembelian penggunaan Gojek di Surabaya tidak melihat citra merek seperti jasa berkualitas, pelayanan memberikan kepuasan, memiliki atribut dan fasilitas, memiliki reputasi yang baik.

\section{Pengaruh Kepercayaan Merek Terhadap Keputusan Pembelian}

Kepercayaan merek berpengaruh terhadap keputusan pembelian pengguna aplikasi Gojek. Artinya konsumen melakukan keputusan pembelian dikarenakan kepercayaan merek dapat memenuhi harapan dan kebutuhan, kebutuhan konsumen, seperti helm dan jas hujan, layanan call center ataupun layanan pengaduan menjadi salah satu alasan meningkatnya kepercayaan merek Gojek dari pelanggannya.

\section{Pengaruh Keamanan Privasi Terhadap Keputusan Pembelian}

Keamanan privasi berpengaruh terhadap keputusan pembelian pengguna aplikasi Gojek. Artinya konsumen melakukan keputusan pembelian dikarenakan perusahaan gojek dan mitra driver menjamin privasi, perusahaan dan mitra driver tidak menggunakandata privasi tersebut di luar transaksi untuk keperluan pribadi ataupun pihak lain.

\section{SIMPULAN}

Hasil dari penelitian ini menunjukkan bahwa citra merek tidak memberikan pengaruh terhadap keputusan pembelian dari pengguna aplikasi Gojek di Surabaya. Sedangkan kepercayaan merek memberikan pengaruh terhadap keputusan pembelian pengguna aplikasi Gojek di Surabaya. Kemudian keamanan privasi juga memberikan pengaruh terhadap keputusan pembelian pengguna aplikasi Gojek di Surabaya.

\section{SARAN}

Kepercayaan merek memiliki hasil yang berpengaruh terhadap keputusan pembelian. Agar dapat tetap dipertahankan dan ditingkatkan, maka perlu bagi perusahaan Gojek untuk memperhatikan juga terkait dengan menyediakan kebutuhan tambahan bagi pelanggan seperti fasilitas yaitu haircap dan masker yang juga sering dibutuhkan oleh konsumen. Ketersediaan fasilitas ini akan mendukung kepercayaan pelanggan dalam memutuskan pembelian pada layanan yang memberikan fasilitas lengkap dalam berkendaraan.

Privasi keamanan hendaknya diperhatikan oleh perusahaan Gojek. Hal ini dikarenakan adanya kepercayaan pelanggan dalam memberikan informasi yang bersifat privasi dalam sistem aplikasi. Konsumen yang harus memberikan informasi pribadi mereka untuk bisa mengakses aplikasi juga harus dijamin 
kerahasiaannya dari perilaku pihak lain yang dapat menggunakan informasi tersebut untuk hal-hal yang berada di luar sistem. Penelitian ini dapat dijadikan acuan atau sumber informasi bagi penelitian yang akan datang yang terkait dengan citra merek, kepercayaan merek, keamanan privasi terhadap keputusan pembelian.

\section{DAFTAR PUSTAKA}

Ali, Intan, Sukma Irdiana, dan Jesi Irwanto. 2019. Dampak Brand Image, Brand Equity, dan Brand Trust Terhadap Keputusan Pembelian Laptop Asus (Studi Pada Toko Komputer Lumajang Computer Centre di Kabupaten Lumajang). Progress Conference, Vol. 2, No. 1, pp. 406- 413.

Anggara, Supriyadi Widodo Eddyono, dan Wahyudi Djafar. 2015. Menyeimbangkan Hak: Tantangan Perlindungan Privasi dan Menjamin Akses Keterbukaan Informasi dan Data di Indonesia. Institute for Criminal Justice Reform. Jakarta.

Delgado-Ballester, Elena and Jose' Luis Munuera-Alema'n. 2005. Does Brand Trust Matter to Brand Equity? Journal of Product and Brand Management, Vol. 14, No. 3, pp. 187-196.

Farohi, Muhammad Irham. 2017. Pengaruh Keamanan dan Kepercayaan Terhadap Keputusan Pembelian Melalui Social Networking Site (Studi Pada Buyer Toko Online Lazada.co.id di Kota Semarang). Skripsi. Universitas Negeri Semarang. Semarang.

Ferrinadewi, Erna. 2009. Merek dan Psikologi Konsumen Implikasi Pada Strategi Pemasaran. Graha Ilmu. Yogyakarta.

Herliza, Radita dan Marheni Eka Saputri. 2016. Pengaruh Brand Image Terhadap Kepausan Pelanggan Studi Pada Zara di Mall PVJ Bandung. E-Proceeding of Management Journal, Vol. 3, No. 02, pp. 1949-1956.

Kotler, Philip. 2014. Manajemen Pemasaran di Indonesia. Edisi 4. Salemba Empat. Jakarta.

Mamahit, Philius, Agus Supandi Soegoto, dan Willem Alfa Tumbuan. 2015. Pengaruh Brand Image, Brand Trust, dan Kualitas Produk Terhadap Keputusan Pembelian Mobil Toyota All New Yaris Pada PT. Hasjrat Abadi Manado. Jurnal Berkala Ilmiah Efisiensi, Vol. 15, No. 5, pp. 777-787.

Raman, Arasu and Annamalai Viswanathan. 2011. Web Services and e-Shopping Decisions: A Study on Malaysian e-Consumer. IJCA Special Issue on Wireless Information Networks \& Business Information System, Vol. 2, pp. 54-60.

Richards, Neil and Woodrow Hartzog. 2016. Taking Trust Seriously in Privacy Law. Stanford Technology Law Review, Vol. 19, Issue 3, pp. 431-472. 
Pengaruh Citra Merek, Kepercayaan Mereß, dan Keamanan Privasi Terhadap Keputusan Pengguna Gojek

Valentine Teja Wijaya dan Bruno Hami Pahar

Rizan, Mohammad, Basrah Saidani, dan Yusiyana Sari. 2012. Pengaruh Brand Image dan Brand Trust Terhadap Brand Loyalty Teh Botol Sosro (Survei Konsumen Teh Botol Sosro di FoodCourt ITC Cempaka Mas Jakarta Timur). Jurnal Riset Manajemen Sains Indonesia, Vol. 3, No. 1, pp. 1-17.

Setiadi, Nugroho J. 2014. Perilaku Konsumen. Edisi 5. Kencana. Jakarta.

Sudaryono. 2016. Manajemen Pemasaran Teori \& Implementasi. Andi. Yogyakarta.

Tjiptono, Fandy. 2014. Pemasaran Jasa - Prinsip, Penerapan, dan Penelitian. Andi Offset. Yogyakarta.

Wahyuningsih, Sri. 2016. Pengaruh Kepercayaan, Keamanan, Syariah Compliance, dan Persepsi Akan Risiko Terhadap Keputusan Pembelian Melalui Situs Jejaring Sosial (Studi Kasus Pada Mahasiswa S1 UIN Walisongo Semarang). Skripsi. Universitas Islam Negeri Walisongo. Semarang.

Wikipedia. 2021. Gojek. https://id.wikipedia.org/wiki/Gojek, Diakses pada tanggal 16 Mei 2021, jam 23.16 WIB.

Yudhistira, Luthfir Rahman dan Asim. 2019. Pengaruh Citra Merek dan Promosi Terhadap Volume Penjualan Pada Divisi Bazaar Transmart Ambasador Jakarta. Jurnal Administrasi dan Manajemen, Vol. 9, No. 1, pp. 78-89.

Zulyanecha, Aldy. 2013. Indikator Keputusan Pembelian. Erlangga. Jakarta. 